\title{
Ankle-brachial index and incident diabetes mellitus: the atherosclerosis risk in communities (ARIC) study
}

Simin Hua ${ }^{1}$, Laura R. Loehr², Hirofumi Tanaka³ , Gerardo Heiss², Josef Coresh', Elizabeth Selvin and Kunihiro Matsushita ${ }^{*}$

\begin{abstract}
Background: Individuals with peripheral artery disease (PAD) often have reduced physical activity, which may increase the future risk of diabetes mellitus. Although diabetes is a risk factor for PAD, whether low ankle-brachial index (ABI) predates diabetes has not been studied.

Methods: We examined the association of ABI with incident diabetes using Cox proportional hazards models in the ARIC Study. ABI was measured in 12,247 black and white participants without prevalent diabetes at baseline (19871989). Incident diabetes cases were identified by blood glucose levels at three subsequent visits (1990-92, 1993-95, and 1996-98) or self-reported physician diagnosis or medication use at those visits or during annual phone interview afterward through 2011.

Results: A total of 3305 participants developed diabetes during a median of 21 years of follow-up. Participants with low $(\leq 0.90)$ and borderline low $(0.91-1.00) \mathrm{ABI}$ had $30-40 \%$ higher risk of future diabetes as compared to those with ABI of 1.10-1.20 in the demographically adjusted model. The associations were attenuated after further adjustment for other potential confounders but remained significant for $\mathrm{ABI} 0.91-1.00(\mathrm{HR}=1.17,95 \% \mathrm{Cl} 1.04-1.31)$ and marginally significant for $\mathrm{ABI} \leq 0.90$ ( $\mathrm{HR}=1.19,0.99-1.43)$. Although the association was largely consistent across subgroups, a stronger association was seen in participants without hypertension, those with normal fasting glucose, and those with a history of stroke compared to their counterparts.
\end{abstract}

Conclusions: Low ABI was modestly but independently associated with increased risk of incident diabetes in the general population. Clinical attention should be paid to the glucose trajectory among people with low ABI but without diabetes.

Keywords: Ankle-brachial index, Peripheral artery disease, Diabetes mellitus, Community-based study, Prospective cohort study

\section{Background}

Lower extremity peripheral arterial disease (PAD), typically defined by an ankle-brachial index $(\mathrm{ABI})<0.9[1]$, affects 8-10 million people in the United States [2]. PAD increases the risk of cardiovascular disease and reduces

\footnotetext{
${ }^{*}$ Correspondence: kmatsush@jhsph.edu

${ }^{1}$ Department of Epidemiology, Johns Hopkins Bloomberg School of Public Health, Welch Center for Prevention, Epidemiology and Clinical Research, 2024 E. Monument Street Suite 2-600, Baltimore, MD 21287, USA

Full list of author information is available at the end of the article
}

quality of life due to ischemic leg pain and intermittent claudication $[1,3,4]$.

Regardless of leg symptoms, patients with PAD experience functional decline and impairment [5-7], which are shown to result in reduced level of physical activity $[8,9]$. For example, a study observed a $20 \%$ decline in accelerometer-measured physical activity level in participants with PAD comparing to those without [8]. Since physically inactivity is an important risk factor of diabetes mellitus [10], it is possible that low $\mathrm{ABI}$ is associated with the development of diabetes. Furthermore, ABI, 
an indicator of severity of atherosclerosis in the legs, is found to be associated with microvascular dysfunction in skeletal muscle which is the largest tissue in the body that is insulin-sensitive and central to glucose utilization and metabolic health $[11,12]$.

However, to the best of our knowledge, the association of $\mathrm{ABI}$ with future risk of diabetes has not yet been studied although the opposite direction of association (i.e., diabetes as a risk factor of PAD) is well-known [2, 13, 14]. Therefore, we aimed to investigate whether ABI is independently associated with incident diabetes in a community-based cohort, the Atherosclerosis Risk in Communities (ARIC) Study.

\section{Methods}

\section{Study population}

The ARIC Study is a community-based prospective cohort study of 15,792 individuals aged 45-64 years at baseline. Participants were recruited at baseline examination (visit 1) during 1987-1989 from four US communities: Forsyth County, North Carolina; Jackson, Mississippi; suburbs of Minneapolis, Minnesota; and Washington County, Maryland [15]. The participants were invited for three short-term follow-up examinations at three-year intervals (visits 2 [1990-1992], 3 [19931995], and 4 [1996-1998]). They also received annual telephone interview regarding their lifestyle and clinical conditions. The study was approved by the institutional review boards at all centers, and informed consent was obtained from all participants.

Of 15,792 participants, we excluded 2309 participants with prevalent diabetes (defined as self-reported physician diagnosis or treatment of diabetes, fasting blood glucose $\geq 126 \mathrm{mg} / \mathrm{dl}$ or random blood glucose $\geq 200 \mathrm{mg} /$ $\mathrm{dl}$ at baseline) and 17 participants with no information about diabetes status. We further excluded 40 non-white and non-black participants as well as those with missing information on ABI $(n=476)$ and any covariates at baseline $(\mathrm{n}=596)$, leaving 12,247 participants in our analysis. Of the study population, $76 \%$ participants attended all follow-up visits 2 through 4 while $88 \%$ attended at least two follow-up visits and $97 \%$ attended at least once. Approximately 92\% participants responded to annual telephone interview after visit 4 examination.

\section{Exposure assessment}

ABI was defined as a ratio of systolic blood pressure of ankle to that of arm. The ankle and brachial blood pressures were measured by Dinamap Model 1846 SX during ultrasound assessment, an oscillometric device that obtains repeated blood pressure measurement automatically $[3,16]$. Before examination, participants were asked to refrain from smoking, vigorous exercise, and drinking coffee, tea, and soft drinks containing caffeine during the night before and the day of examination [16]. Ankle systolic blood pressure was measured four times in a randomly selected leg and the last non-missing value was used as numerator of ABI. Brachial systolic blood pressure was measured twice in the right arm and the first non-missing value was used as denominator of $A B I$ [17]. According to a previous study, the reliability of the ABI based on single ankle and arm systolic blood pressure was $0.61(95 \%$ CI $0.50,0.70)$ [18].

\section{Outcome assessment}

The ascertainment of incident diabetes mellitus was based on two elements, self-reported physician diagnosis or treatment of diabetes during visits or phone interview through April 18, 2011 (interview-based definition) and fasting blood glucose $\geq 126 \mathrm{mg} / \mathrm{dl}(7.0 \mathrm{mmol} / \mathrm{l})$, random blood glucose $\geq 200 \mathrm{mg} / \mathrm{dl}$ ( $11.1 \mathrm{mmol} / \mathrm{l})$, or self-reported physician diagnosis or treatment of diabetes during visits 2 through 4 (visit-based definition), as previously done [19]. Participants who did not develop diabetes during follow-up were censored due to death, loss to follow-up, or end of follow-up. To maximize the statistical power, as the primary outcome, we combined these two definitions but also analyzed them separately as a secondary analysis.

\section{Covariates of interest}

Age, gender, race, parental history of diabetes, medical history of coronary heart disease (CHD) and stroke/ transient ischemic attack (TIA), smoking and alcohol drinking habits and exertional leg pain were selfreported at baseline. Medication use was assessed by self-report and examination of medication containers brought to the visit. Height, weight, and sitting blood pressure were measured according to standardized protocols. Hypertension was defined as a systolic blood pressure $\geq 140 \mathrm{mmHg}$ or a diastolic blood pressure $\geq 90 \mathrm{mmHg}$, or use of antihypertensive drugs. Total cholesterol level, high-density lipoprotein cholesterol level, and triglyceride level were measured using enzymatic determination methods. Glucose was measured using the hexokinase-glucose-6-phosphate dehydrogenase method, as detailed previously [19]. White blood cell count was measured by automated hematology analyzer [20]. Fibrinogen was measured using assay according to standard procedures [21]. Physical activity was assessed with the Baecke physical activity questionnaire, which recorded the duration, intensity and frequency of physical activity at work, in leisure time and during sports and produced an index score to represent level of physical activity [22]. 


\section{Statistical analyses}

We categorized ABI into seven groups, $\mathrm{ABI} \leq 0.90$, $0.90<\mathrm{ABI} \leq 1.00$ (denoted as 0.91-1.00), 1.01-1.10, 1.11-1.20, 1.21-1.30, 1.31-1.40 and >1.40, consistent with prior literature [3]. Baseline characteristics were compared across these groups, according to Chi square test and ANOVA, as appropriate.

To visualize potentially non-linear associations, we estimated incidence rates of diabetes according to ABI with its linear spline terms (knots at 0.9, 1.0, 1.1, 1.2, 1.3 and 1.4) using Poisson regression models. We subsequently quantified the adjusted risk of incident diabetes according to the seven ABI categories using Cox proportional hazards models. ABI 1.11-1.20 was used as the reference group since this group was used as the reference in an international meta-analysis and had the largest number of participants in our study [23]. To evaluate the impact of potential confounding, we constructed three models. Model 1 was adjusted for age, sex and race. Model 2 included all variables in Model 1 plus factors associated with atherosclerosis and diabetes, namely body mass index, total cholesterol, high-density lipoprotein cholesterol, and triglyceride, drinking and smoking status (current, former, and never), systolic blood pressure, hypertension medication use, history of CHD, stroke or TIA, statin use, parental history of diabetes, white blood cell count, and physical activity index. Models 3 and 4 included all variables in Model 2 plus baseline fasting glucose or homeostatic model assessment of insulin resistance (HOMA-IR), respectively. There was no major deviation from the proportional hazards assumption for ABI categories based on visual evaluation from $\log -\log$ plot as well as from test on Schoenfeld residuals.

To evaluate whether the association is consistent across demographic and clinical subgroups, we tested for interaction and conducted subgroup analyses by age ( $\leq$ vs. $>55$ years), gender, race, smoking status (current vs. former/never), history of cardiovascular disease, history of stroke or TIA, hypertension status, baseline fasting glucose level [normal $<100(<5.6 \mathrm{mmol} / \mathrm{l})$ vs. impaired $100-125 \mathrm{mg} / \mathrm{dl}(5.6-6.9 \mathrm{mmol} / \mathrm{l})]$ and exertional leg pain status. Interaction was tested by incorporating a product term of ABI categories and subgroups in Cox models.

As a sensitivity analysis, we repeated the analysis in visit-based definition and interview-based definition of diabetes separately. We also explored the model which replaced white blood cell count with fibrinogen (an alternative inflammatory marker) in Model 2. Finally, we treated physical activity, a potential mediator of ABIdiabetes association, as a time-varying covariate using self-report data assessed at visit 3 in addition to Model 2 covariates.
All analyses were performed with Stata version 12.0. All $p$ values were two-sided, and $p<0.05$ was considered statistically significant.

\section{Results}

The mean ABI of study population was 1.13 (SD 0.14). There were 455 individuals (3.7\%) with $\mathrm{ABI} \leq 0.90$ and 1529 participants (12.5\%) with borderline low ABI of 0.91-1.00. There was no significant correlation between $\mathrm{ABI}$ and baseline fasting glucose $(\mathrm{r}=0.002$, $\mathrm{p}$ value $=0.81$ ). Baseline characteristics of study participants by ABI categories are shown in Table 1 . As compared to participants with ABI 1.11-1.20 (reference group), those with lower ABI were more likely to be older, female, and blacks. They also had worse cardiovascular risk profiles relative to the reference group, including higher prevalence of current smokers, hypertension, and cardiovascular diseases (CHD and stroke/TIA), higher levels of body mass index, total cholesterol, triglyceride, white blood cell count, and fibrinogen, and lower level of physical activity. Participants with $\mathrm{ABI}>1.40$, indicative of arterial calcification [24], also had worse cardiovascular risk profiles as compared to those with $\mathrm{ABI}$ 1.11-1.20. The fasting glucose levels are similar across ABI categories. However, participants with $\mathrm{ABI} \leq 0.90$ and $\mathrm{ABI}>1.40$ had higher levels of fasting insulin and HOMA-IR than the rest groups.

A total of 3305 cases of incident diabetes were identified during a median of 21 years of follow-up (incidence rate 16.8 [95\% CI 15.8-16.9] per 1000 person-years). Figure 1 shows demographically adjusted incidence rates of diabetes according to ABI at baseline. The incidence rates of diabetes were lowest in ABI 1.10-1.30 and increased below this range. The incidence rate of diabetes was similar or slightly higher in $\mathrm{ABI}>1.30$ compared to $\mathrm{ABI}$ 1.10-1.30.

In a demographically adjusted Cox regression model with ABI 1.10-1.20 as the reference, lower ABI categories were significantly associated with incident diabetes (hazard ratio [HR] 1.41 [95\% CI 1.17-1.68] for ABI $\leq 0.90$, 1.29 [1.15-1.45] for ABI 0.91-1.00, and 1.10 [1.00-1.22] for ABI 1.01-1.10, Model 1 in Table 2). When we further adjusted for other potential confounders including traditional cardiovascular risk factors, white blood cell count, and physical activity (Model 2 in Table 2), the associations for all lower ABI categories remained significant although it was borderline significant for $\mathrm{ABI} \leq 0.90$. The replacement of white blood cell count with fibrinogen did not make material difference (data not shown). After accounting for baseline fasting glucose (Model 3), the association remained marginally significant only in participants with ABI 0.91-1.00 ( $\mathrm{p}$ value $=0.051)$. However, when we combined low $\mathrm{ABI} \leq 0.90$ and borderline low 
Table 1 Baseline characteristics of participants without prevalent diabetes by ABI categories

\begin{tabular}{|c|c|c|c|c|c|c|c|}
\hline Characteristics & $\mathrm{ABI} \leq 0.90$ & $0.91-1.00$ & $1.01-1.10$ & $1.11-1.20$ & $1.21-1.30$ & $1.31-1.40$ & $\mathrm{ABI}>1.40$ \\
\hline$N(\%)$ & $455(3.7)$ & $1529(12.5)$ & $2894(23.6)$ & 3633 (29.7) & 2509 (20.5) & $924(7.5)$ & $303(2.5)$ \\
\hline $\begin{array}{l}\text { Age, mean (SD), } \\
\text { years }^{a}\end{array}$ & $54.9(5.9)$ & $53.7(5.8)$ & $53.4(5.6)$ & $53.9(5.8)$ & $53.9(5.6)$ & $54.6(5.7)$ & $55.1(5.7)$ \\
\hline Female, no. $(\%)^{\mathrm{a}}$ & $321(70.6)$ & $1116(73.0)$ & $1867(64.5)$ & 1903 (52.4) & $1104(44.0)$ & $373(40.4)$ & $125(41.3)$ \\
\hline Black, no. $(\%)^{a}$ & $121(26.6)$ & $357(23.4)$ & $700(24.2)$ & $867(23.9)$ & $542(21.6)$ & $177(19.2)$ & $47(15.5)$ \\
\hline $\begin{array}{l}\text { BMI, mean (SD), kg/ } \\
\mathrm{m}^{2 a}\end{array}$ & $27.7(6.0)$ & $27.7(5.8)$ & $27.1(5.2)$ & $27.0(4.7)$ & $27.0(4.6)$ & $27.4(4.8)$ & $28.3(5.5)$ \\
\hline $\begin{array}{l}\text { Height, mean (SD), } \\
\mathrm{cm}^{\mathrm{a}}\end{array}$ & $165.2(8.9)$ & $165.5(8.5)$ & $167.0(9.0)$ & $169.2(9.3)$ & $170.5(9.3)$ & $171.4(9.5)$ & $170.3(9.5)$ \\
\hline $\begin{array}{l}\text { Current drinker, no. } \\
(\%)^{\mathrm{a}}\end{array}$ & $244(53.6)$ & $874(57.2)$ & $1698(58.7)$ & $2189(60.3)$ & $1525(60.8)$ & $550(59.5)$ & $163(53.8)$ \\
\hline $\begin{array}{l}\text { Current smoker, no. } \\
(\%)^{a}\end{array}$ & $167(36.7)$ & $440(28.8)$ & $798(27.6)$ & $855(23.5)$ & $602(24.0)$ & $195(21.1)$ & $63(20.8)$ \\
\hline $\begin{array}{l}\text { Arm SBP, mean (SD), } \\
\quad \mathrm{mmHg}^{\mathrm{a}}\end{array}$ & $123.0(19.7)$ & $121.0(19.2)$ & $120.3(18.8)$ & $119.7(17.5)$ & $118.2(16.6)$ & $118.0(15.8)$ & $117.6(15.3)$ \\
\hline $\begin{array}{l}\text { Heart rate. mean } \\
(\mathrm{SD}), / \mathrm{min}^{\mathrm{a}}\end{array}$ & $68.5(11.4)$ & $67.7(10.5)$ & $66.9(9.7)$ & $65.8(9.6)$ & $64.5(9.6)$ & $64.3(9.4)$ & $64.2(9.8)$ \\
\hline $\begin{array}{l}\text { Hypertension medi- } \\
\text { cation, no. (\%) }\end{array}$ & $169(37.1)$ & $449(29.4)$ & $810(28.0)$ & $932(25.7)$ & $587(23.4)$ & $221(23.9)$ & $95(31.4)$ \\
\hline $\begin{array}{l}\text { Prevalent CHD, no. } \\
(\%)^{\mathrm{a}}\end{array}$ & $30(6.6)$ & $68(4.5)$ & $103(3.6)$ & $137(3.8)$ & $103(4.1)$ & $38(4.1)$ & $20(6.6)$ \\
\hline $\begin{array}{l}\text { History of stroke or } \\
\text { TIA, no. }(\%)^{\mathrm{a}}\end{array}$ & $33(7.3)$ & $68(4.5)$ & $123(4.3)$ & $151(4.2)$ & $99(4.0)$ & $26(2.8)$ & $15(5.0)$ \\
\hline $\begin{array}{l}\text { Total cholesterol, } \\
\text { mean (SD), mmol//a }\end{array}$ & $5.8(1.1)$ & $5.6(1.0)$ & $5.6(1.1)$ & $5.5(1.1)$ & $5.5(1.0)$ & $5.5(1.0)$ & $5.5(1.1)$ \\
\hline $\begin{array}{l}\mathrm{HDL} \text {, mean (SD), } \\
\mathrm{mmol} / \mathrm{l}^{\mathrm{a}}\end{array}$ & $1.4(0.5)$ & $1.4(0.5)$ & $1.4(0.5)$ & $1.4(0.4)$ & $1.3(0.4)$ & $1.3(0.4)$ & $1.3(0.4)$ \\
\hline $\begin{array}{l}\text { Triglyceride, median } \\
(\mathrm{IQR}), \mathrm{mmol} / \mathrm{l}^{\mathrm{a}}\end{array}$ & $1.3(0.9-1.8)$ & $1.2(0.9-1.6)$ & $1.2(0.8-1.6)$ & $1.2(0.9-1.7)$ & $1.2(0.9-1.7)$ & $1.2(0.9-1.7)$ & $1.3(0.9-1.8)$ \\
\hline Statin use, no. (\%) & $5(1.1)$ & $13(0.9)$ & $16(0.6)$ & $12(0.3)$ & $9(0.4)$ & $5(0.5)$ & $2(0.7)$ \\
\hline $\begin{array}{l}\text { Fasting glucose, } \\
\text { mean (SD), mmol/l }\end{array}$ & $5.5(0.5)$ & $5.5(0.5)$ & $5.5(0.5)$ & $5.5(0.5)$ & $5.5(0.5)$ & $5.5(0.5)$ & $5.5(0.5)$ \\
\hline $\begin{array}{l}\text { Fasting insulin, } \\
\text { median }(25,75 \%), \\
\text { pmol/// }\end{array}$ & $71.8(43.1-107.6)$ & $64.6(43.1-100.5)$ & $64.6(43.1-93.3)$ & $64.6(43.1-93.3)$ & $64.6(43.1-93.3)$ & $64.6(43.1-93.3)$ & $71.8(43.1-107.6)$ \\
\hline $\begin{array}{l}\text { HOMA-IR, median } \\
\qquad(25,75 \%)^{\mathrm{a}}\end{array}$ & $2.8(1.8-4.3)$ & $2.6(1.7-4.0)$ & $2.5(1.6-4.0)$ & $2.5(1.6-3.9)$ & $2.5(1.7-3.8)$ & $2.6(1.7-4.0)$ & $2.8(1.7-4.6)$ \\
\hline $\begin{array}{l}\text { Parental history of } \\
\text { diabetes, no. (\%) }\end{array}$ & $104(22.9)$ & $363(23.7)$ & $633(21.9)$ & $809(22.3)$ & $580(23.1)$ & $190(20.6)$ & $76(25.1)$ \\
\hline $\begin{array}{l}\text { White blood cell } \\
\text { count, median }(25, \\
75 \%), 10^{3 a}\end{array}$ & $6.3(5.1-7.5)$ & $5.9(4.9-7.2)$ & $5.8(4.8-7.0)$ & $5.6(4.7-6.9)$ & $5.6(4.7-6.9)$ & $5.7(4.7-6.8)$ & $5.6(4.7-6.9)$ \\
\hline $\begin{array}{l}\text { Fibrinogen, median } \\
\qquad(25,75 \%), \mathrm{mg} / \mathrm{dl}^{\mathrm{a}}\end{array}$ & $314(277-362)$ & $295(261-342)$ & $295(260-336)$ & $288(255-327)$ & $285(255-324)$ & $286(254-323)$ & $294(261-333)$ \\
\hline $\begin{array}{l}\text { Physical activity } \\
\text { index, mean (SD) }^{\text {a }}\end{array}$ & $6.7(1.5)$ & $6.9(1.5)$ & $7.0(1.4)$ & $7.1(1.4)$ & $7.2(1.4)$ & $7.2(1.4)$ & $7.2(1.5)$ \\
\hline
\end{tabular}

$A B I$ ankle-brachial index, $B M I$ body mass index, $S B P$ systolic blood pressure, $D B P$ diastolic blood pressure, $T I A$ transient ischemic attack, $C H D$ coronary heart disease, $H D L$ high density cholesterol, HOMA-IR homeostatic model assessment of insulin resistance

a Indicates statistically significant difference among $A B I$ groups

0.91-1.00 groups, the association was statistically significant even in Model 3 (HR $=1.12$ [95\% CI 1.01-1.24], $\mathrm{p}$ value $=0.034)$. The associations between $\mathrm{ABI} \leq 0.90$ and ABI 0.91-1.00 with incident diabetes were slightly stronger than those in model 3 when we further adjusted for HOMA-IR in addition to model 2 (Model 4). For participants with $\mathrm{ABI}>1.40$, we observed slight but non-significant increase in the risk of incident diabetes compared to those with ABI 1.11-1.20 in Models 1 and 3. The association was largely consistent when we analyzed interview-based cases and visit-based cases separately (Additional file 1: Tables S1, S2). The model with physical activity as a time-varying covariate using visit 3 data showed similar results (data not shown). 


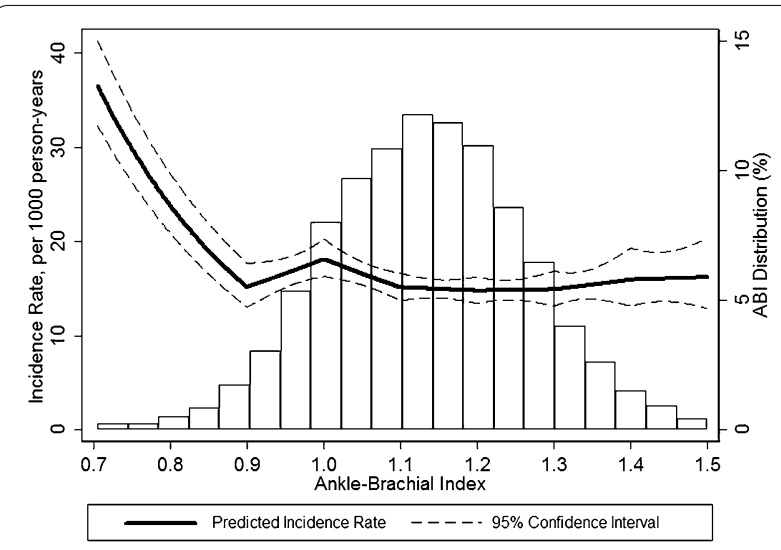

Fig. 1 Demographically adjusted incidence rates of diabetes according to $A B I$ and distribution of $A B I$. Graphed for 0.5-99.5 percentile of $A B I$ values. Adjusted to mean age, white and male

To obtain reliable estimates in subgroup analyses, we dichotomized ABI at below and above 1.00. Given slight increase in the risk of diabetes in some models, those with $\mathrm{ABI}>1.40$ were excluded from this analysis. We observed significant difference in participants with vs. without history of stroke/TIA (HR 1.56 [95\% CI 1.09-2.24] vs. 1.05 [0.95-1.15], p value for interaction $=0.034)$ and in those with vs. without hypertension (HR 0.96 [0.84-1.10] vs. 1.18 [95\% CI 1.05-1.33], p value for interaction $=0.024$ ) (Table 3 ). We also observed borderline significant difference between those with normal vs. impaired fasting glucose (HR 1.20 [95\% CI 1.04-1.39] vs. $1.01[0.90-1.14], \mathrm{p}$ value for interaction $=0.067)$. The higher risk of diabetes was confirmed for both ABI categories of $\leq 0.90$ and $0.91-1.00$ in participants with normal fasting glucose, those without hypertension, and those with a history of stroke/TIA (Additional file 1: Tables S3, S4, S5).

\section{Discussion}

To our knowledge, this is the first study to examine the association between $\mathrm{ABI}$ and the future risk of diabetes. We found that low and borderline low ABI $(\leq 1.0)$ was associated with a moderately increased risk of diabetes. The association was independent of other atherosclerotic cardiovascular diseases, physical activity, and other potential confounders. Further adjustment for fasting glucose levels attenuated the association, but $\mathrm{ABI} \leq 1.0$ showed significantly higher risk of diabetes compared to ABI 1.11-1.20 even in this model. Largely similar results were observed in demographic and clinical subgroups, although the associations tended to be stronger in participants without hypertension, those with normal fasting glucose, and those with history of stroke/TIA compared to their counterparts.

In terms of potential mechanisms, as we hypothesized, impaired physical activity related to PAD may play a role. However, in our study, the ABI-diabetes relationship remained significant after accounting for physical activity. Yet, we need to bear in mind that physical activity was based on self-report [25]. Also, there are a few other potential mechanisms linking low ABI to future diabetes risk. ABI is a marker of systematic atherosclerosis [26], and participants with low ABI indeed had worse cardiovascular risk profiles in our study. Several traditional cardiovascular risk factors such as hypertension, smoking, and dyslipidemia are known to be related to high risk of developing diabetes [27-29]. Thus, we rigorously adjusted for these traditional risk factors but still observed significant associations between ABI and risk of diabetes. Also, endothelial dysfunction, an early condition of atherosclerosis, may be a contributor. It has been shown that delayed insulin delivery can occur due to endothelial dysfunction [30]. Indeed, endothelial dysfunction is associated with future risk of type 2 diabetes in a few studies [31, 32]. In addition, shared pathophysiology such as inflammation is

Table 2 Hazard ratios of diabetes in different ABI categories

\begin{tabular}{|c|c|c|c|c|c|c|c|c|}
\hline & $A B I$ & $\leq 0.90$ & $0.91-1.00$ & $1.01-1.10$ & $1.11-1.20$ & $1.21-1.30$ & $1.31-1.40$ & $>1.40$ \\
\hline N & 12,247 & 455 & 1529 & 2894 & 3633 & 2509 & 924 & 303 \\
\hline Number of events & 3305 & 137 & 457 & 781 & 927 & 668 & 249 & 86 \\
\hline \multirow[t]{2}{*}{ Model 1} & $H R$ & 1.41 & 1.29 & 1.10 & Ref & 1.06 & 1.07 & 1.16 \\
\hline & $95 \% \mathrm{Cl}$ & $1.17-1.68$ & $1.15-1.45$ & $1.00-1.22$ & - & $0.96-1.17$ & $0.93-1.23$ & $0.93-1.45$ \\
\hline \multirow[t]{2}{*}{ Model 2} & $\mathrm{HR}$ & 1.20 & 1.17 & 1.10 & Ref & 1.08 & 1.10 & 1.01 \\
\hline & $95 \% \mathrm{Cl}$ & $0.99-1.43$ & $1.04-1.31$ & $1.00-1.21$ & - & $0.98-1.20$ & $0.96-1.27$ & $0.81-1.27$ \\
\hline \multirow[t]{2}{*}{ Model 3} & $H R$ & 1.12 & 1.12 & 1.08 & Ref & 1.06 & 1.09 & 1.12 \\
\hline & $95 \% \mathrm{Cl}$ & $0.94-1.34$ & $0.99-1.26$ & $0.98-1.18$ & - & $0.96-1.17$ & $0.94-1.25$ & $0.90-1.40$ \\
\hline \multirow[t]{2}{*}{ Model 4} & $H R$ & 1.18 & 1.14 & 1.09 & Ref & 1.09 & 1.10 & 1.00 \\
\hline & $95 \% \mathrm{Cl}$ & $0.98-1.41$ & $1.02-1.28$ & $0.99-1.20$ & - & $0.99-1.21$ & $0.95-1.26$ & $0.80-1.25$ \\
\hline
\end{tabular}

Model 1, adjusted for age, gender and race; Model 2, adjusted for age, gender, race, current and former drinking, current and former smoking, BMI, SBP, hypertension medication, HDL, total cholesterol, log (triglyceride), prevalent CHD, stroke or TIA, statin use, parental history of diabetes, log (white blood cell count) and Baecke physical activity index; Model 3, adjusted for baseline fasting glucose in addition to model 2; Model 4, adjusted for baseline log (HOMA-IR) in addition to model 2 
Table 3 Hazard ratios of diabetes in different subgroups

\begin{tabular}{|c|c|c|}
\hline Subgroup & $\begin{array}{l}\mathrm{HR} \text { and } 95 \% \mathrm{Cl} \\
\mathrm{ABI} \leq 1.00 \text { vs } 1.01-1.40\end{array}$ & $\begin{array}{l}\text { p value for inter- } \\
\text { action }\end{array}$ \\
\hline All & $1.07(0.98,1.17)$ & - \\
\hline Gender & & 0.46 \\
\hline Male (5260) & $1.13(0.96-1.33)$ & \\
\hline Female (6684) & $1.05(0.94-1.17)$ & \\
\hline Race & & 0.89 \\
\hline White (9180) & $1.08(0.97-1.20)$ & \\
\hline Black (2764) & $1.06(0.90-1.25)$ & \\
\hline Age & & 0.35 \\
\hline$\leq 55(7193)$ & $1.04(0.92-1.17)$ & \\
\hline$>55(4751)$ & $1.13(0.98-1.30)$ & \\
\hline Current smoking & & 0.77 \\
\hline No (8887) & $1.07(0.96-1.19)$ & \\
\hline Yes (3057) & $1.10(0.93-1.30)$ & \\
\hline Prevalent CHD & & 0.41 \\
\hline No $(11,465)$ & $1.08(0.99-1.19)$ & \\
\hline Yes (479) & $0.89(0.58-1.39)$ & \\
\hline History of stroke/TIA & & 0.034 \\
\hline No $(11,444)$ & $1.05(0.95-1.15)$ & \\
\hline Yes (500) & $1.56(1.09-2.24)$ & \\
\hline Hypertension & & 0.024 \\
\hline No (8923) & $1.18(1.05-1.33)$ & \\
\hline Yes (3622) & $0.96(0.84-1.10)$ & \\
\hline $\begin{array}{l}\text { Family history of } \\
\text { diabetes }\end{array}$ & & 0.37 \\
\hline No (9625) & $1.04(0.93-1.16)$ & \\
\hline Yes (2679) & $1.14(0.97-1.34)$ & \\
\hline $\begin{array}{l}\text { Baseline FBG } \\
5.6-6.9 \mathrm{mmol} / /\end{array}$ & & 0.067 \\
\hline No (6895) & $1.20(1.04-1.39)$ & \\
\hline Yes (5049) & $1.01(0.90-1.14)$ & \\
\hline $\begin{array}{l}\text { Leg pain while walk- } \\
\text { ing }\end{array}$ & & 0.58 \\
\hline No (9606) & $1.05(0.95-1.17)$ & \\
\hline Yes (2338) & $1.12(0.94-1.33)$ & \\
\hline
\end{tabular}

$\mathrm{N}=11,944$

Excluded $A B I>1.4$ and adjusted for age, gender, race, current and former drinking, current and former smoking, BMI, SBP, hypertension medication, $\mathrm{HDL}$, total cholesterol, log (triglyceride), prevalent CHD, stroke or TIA, statin use, parental history of diabetes, log (white blood cell count), Baecke physical activity index and fasting glucose

known for atherosclerosis and insulin resistance [33, 34]. Although chronic inflammation can be a common ground for development of both atherosclerosis and diabetes [3336], our results were not altered with adjustment for white blood cell count or fibrinogen.

We found that the association between low and borderline low $\mathrm{ABI}(\leq 1.00)$ and risk of diabetes tended to be stronger in participants without hypertension, those with normal fasting glucose, and those with a history of stroke/ TIA as compared to their counterparts. We are not necessarily sure about mechanisms behind these suggestive interactions, but there may be a few potential explanations for null association in participants with hypertension or elevated glucose level. Many of those with hypertension were treated with antihypertensive medications (72\%), which might confound the ABI-diabetes association to null among hypertensive patients. Indeed, renin-angiotensin system inhibitors are reported to reduce the risk of diabetes [37], whereas diuretics and beta blockers may contribute to increased risk of developing diabetes [38]. For people with impaired fasting glucose, who are known to have reduced insulin sensitivity and $\beta$ cell dysfunction [39], a mild single predictor such as ABI may not considerably contribute to discriminating their diabetes risk since they are already at high risk of diabetes. Nonetheless, we need to keep in mind that we have tested multiple subgroups without a priori hypothesis, and thus, our subgroup analysis should be interpreted as hypothesis-generating.

\section{Clinical and research implications of the study}

Although our findings need to be confirmed in other settings, there may be a few clinical and research implications from our study. Our study demonstrates future diabetes as another adverse clinical consequence of PAD in addition to its known complications such as other cardiovascular diseases and impaired functional status $[3,4$, $7,26,40-44]$. This finding is important given the adverse outcomes associated with diabetes [44-49]. Since some clinical guidelines recommend screening of PAD using the $A B I$ in individuals with advanced age and/or traditional cardiovascular risk factors $[1,50]$, attention should be given to monitoring glucose levels among individuals with low or borderline low ABI even though their fasting glucose is within the normal range at baseline. If our results are replicated, it would be worth assessing whether PAD-specific interventions (e.g., supervised exercise [51]) have beneficial effects on glucose metabolism and whether other measures of subclinical atherosclerosis (e.g., carotid intra-media thickness or coronary artery calcium) are related to incident diabetes.

\section{Limitations of the study}

Our study has several limitations. First, ABI was measured once for a randomly selected leg at baseline. The prevalence of low ABI may be underestimated as a result of missing low ABI in the opposite leg in some participants. Second, there were 15 years of follow-up where incident diabetes cases were solely based on selfreport (interview-based definition). However, as aforementioned, the association was largely consistent for 
visit-based and interview-based diabetes. Third, we were not able to adjust for baseline hemoglobin A1c as it was not available at visit 1 . Fourth, our study participants were 45-64 years old at baseline, and thus the generalization of our results to adults in other age ranges should be done with caution. Finally, like other observational studies, residual confounding cannot be denied.

\section{Conclusions}

Low ABI $(\leq 1.00)$ was modestly but independently associated with increased risk of future diabetes in communitybased middle-aged populations. Although future studies are needed to confirm our findings and investigate potential mechanisms, our study suggests that clinical attention should be given to glucose trajectory in people with low or borderline low ABI.

\section{Additional file}

Additional file 1. Online supplementary tables.

\begin{abstract}
Abbreviations
PAD: peripheral artery disease; $\mathrm{ABI}$ : ankle-brachial index; HR: hazard ratio; $\mathrm{Cl}$ : confidence interval; ARIC: the Atherosclerosis Risk in Communities Study; CHD: coronary heart disease; TIA: transient ischemic attack; ANOVA: analysis of variance; BMI: body mass index; SBP: systolic blood pressure; DBP: diastolic blood pressure; HDL: high density cholesterol; FBG: fasting blood glucose; HOMA-IR: homeostatic model assessment of insulin resistance.
\end{abstract}

\section{Authors' contributions}

SH contributed to the study concept, conducted the analyses and drafted the manuscript. KM contributed to the study concept, supervised the analyses, interpreted data, and edited the manuscript. ES, HT, LRL, GH and JC interpreted data and critically reviewed the manuscript. KM is the guarantor of this work and as such, has full access to the data in the study and takes full responsibility for the data integrity, data analysis and interpretation of scientific findings. All authors read and approved the final manuscript.

\section{Author details}

${ }^{1}$ Department of Epidemiology, Johns Hopkins Bloomberg School of Public Health, Welch Center for Prevention, Epidemiology and Clinical Research, 2024 E. Monument Street Suite 2-600, Baltimore, MD 21287, USA. ${ }^{2}$ Department of Epidemiology, The University of North Carolina at Chapel Hill Gillings School of Global Public Health, 137 East Franklin Street, Suite 306, Chapel Hill, NC 27514, USA. ${ }^{3}$ Department of Kinesiology \& Health Education, The University of Texas at Austin, 2109 San Jacinto Blvd, Austin, TX 78712-1415, USA.

\section{Acknowledgements}

The authors thank the staff and participants of the ARIC study for their important contributions.

\section{Competing interests}

The authors declare that they have no competing interests.

\section{Availability of data and material}

Detailed policies for accessing ARIC data can be found at https://www2.cscc. unc.edu/aric/pubs-policies-and-forms-pg. It is also possible to obtain the study's data from the NHLBI BioLINCC repository (https://biolincc.nhlbi.nih. gov/home/).

\section{Ethics approval and consent to participate}

The study was approved by the institutional review boards at all field centers of ARIC study, and informed consent was obtained from all participants.

\section{Funding}

The Atherosclerosis Risk in Communities Study is supported by National Heart, Lung, and Blood Institute contracts (HHSN268201100005C, HHSN268201100006C, HHSN268201100007C, HHSN268201100008C, HHSN268201100009C, HHSN268201100010C, HHSN268201100011C, and HHSN268201100012C). ES was supported by NIH/NIDDK grants K24DK106414 and R01DK089174.

Received: 20 July 2016 Accepted: 22 November 2016 Published online: 07 December 2016

\section{References}

1. Hirsch AT, Haskal ZJ, Hertzer NR, Bakal CW, Creager MA, Halperin JL, Hiratzka LF, Murphy WR, Olin JW, Puschett JB, et al. ACC/AHA 2005 practice guidelines for the management of patients with peripheral arterial disease (lower extremity, renal, mesenteric, and abdominal aortic): a collaborative report from the American Association for Vascular Surgery/ Society for Vascular Surgery, Society for Cardiovascular Angiography and Interventions, Society for Vascular Medicine and Biology, Society of Interventional Radiology, and the ACC/AHA Task Force on Practice Guidelines (Writing Committee to Develop Guidelines for the Management of Patients With Peripheral Arterial Disease): endorsed by the American Association of Cardiovascular and Pulmonary Rehabilitation; National Heart, Lung, and Blood Institute; Society for Vascular Nursing; Transatlantic Inter-Society Consensus; and Vascular Disease Foundation. Circulation. 2006;113(11):e463-654.

2. Roger VL, Go AS, Lloyd-Jones DM, Benjamin EJ, Berry JD, Borden WB, Bravata DM, Dai S, Ford ES, Fox CS, et al. Heart disease and stroke statistics - 2012 update: a report from the American Heart Association. Circulation. 2012;125(1):e2-220.

3. Weatherley BD, Nelson JJ, Heiss G, Chambless LE, Sharrett AR, Nieto FJ, Folsom AR, Rosamond WD. The association of the ankle-brachial index with incident coronary heart disease: the Atherosclerosis Risk in Communities (ARIC) study, 1987-2001. BMC Cardiovasc Disord. 2007;7:3.

4. Spronk S, White JV, Bosch JL, Hunink MG. Impact of claudication and its treatment on quality of life. Sem Vasc Surg. 2007;20(1):3-9.

5. McDermott MM, Liu K, Greenland P, Guralnik JM, Criqui MH, Chan C, Pearce WH, Schneider JR, Ferrucci L, Celic L, et al. Functional decline in peripheral arterial disease: associations with the ankle brachial index and leg symptoms. JAMA. 2004;292(4):453-61.

6. Selvin E, Hirsch AT. Contemporary risk factor control and walking dysfunction in individuals with peripheral arterial disease: NHANES 1999-2004. Atherosclerosis. 2008;201(2):425-33.

7. Wassel CL, Allison MA, Ix JH, Rifkin DE, Forbang NI, Denenberg JO, Criqui $\mathrm{MH}$. Ankle-brachial index predicts change over time in functional status in the San Diego Population Study. J Vasc Surg. 2016:64(3):656-62.

8. McDermott MM, Greenland P, Ferrucci L, Criqui MH, Liu K, Sharma L, Chan C, Celic L, Priyanath A, Guralnik JM. Lower extremity performance is associated with daily life physical activity in individuals with and without peripheral arterial disease. J Am Geriatr Soc. 2002;50(2):247-55.

9. Hawkins MS, Gabriel KP, Conroy MB, Cooper J, Sutton-Tyrrell K. Physical activity intensity and cardiovascular risk by ankle-brachial index. Vasc Med. 2013;18(2):79-84.

10. Gill JM, Cooper AR. Physical activity and prevention of type 2 diabetes mellitus. Sports Med. 2008;38:807-24.

11. Wu WC, Mohler E 3rd, Ratcliffe SJ, Wehrli FW, Detre JA, Floyd TF. Skeletal muscle microvascular flow in progressive peripheral artery disease: assessment with continuous arterial spin-labeling perfusion magnetic resonance imaging. J Am Coll Cardiol. 2009;53(25):2372-7.

12. Stump CS, Henriksen EJ, Wei Y, Sowers JR. The metabolic syndrome: role of skeletal muscle metabolism. Ann Med. 2006;38(6):389-402.

13. Althouse AD, Abbott JD, Forker AD, Bertolet M, Barinas-Mitchell E, Thurs ton RC, Mulukutla S, Aboyans V, Brooks MM, BARI 2D Study Group. Risk factors for incident peripheral arterial disease in type 2 diabetes: results from the bypass angioplasty revascularization investigation in type 2 diabetes (BARI 2D) trial. Diabetes Care. 2014;37(5):1346-52.

14. Tapp RJ, Balkau B, Shaw JE, Valensi P, Cailleau M, Eschwege E, DESIR Study Group. Association of glucose metabolism, smoking and cardiovascular 
risk factors with incident peripheral arterial disease: the DESIR study. Atherosclerosis. 2007;190(1):84-9.

15. The ARIC Investigators. The atherosclerosis risk in communities (ARIC) study: design and objectives. Am J Epidemiol. 1989;129(4):687-702.

16. ARIC Protocol Manual 6. Ultrasound Assessment Part A: ultrasound scanning Version 1.0. https://www2.cscc.unc.edu/aric/cohort-manuals.

17. ARIC Data Book: ankle brachial index data. https://www2.cscc.unc.edu/ aric/cohort-forms-forms.

18. Weatherley BD, Chambless LE, Heiss G, Catellier DJ, Ellison CR. The reliability of the ankle-brachial index in the atherosclerosis risk in communities (ARIC) study and the NHLBI Family Heart Study (FHS). BMC CardiovasC Disord. 2006;6:7

19. Selvin E, Steffes MW, Zhu H, Matsushita K, Wagenknecht L, Pankow J, Coresh J, Brancati FL. Glycated hemoglobin, diabetes, and cardiovascular risk in nondiabetic adults. N Engl J Med. 2010;362(9):800-11.

20. ARIC Protocol Manual 7. Blood collection and processing Version 1.1. https://www2.cscc.unc.edu/aric/cohort-manuals.

21. ARIC Protocol Manual 9. Hemostasis determinations. https://www2.cscc unc.edu/aric/cohort-manuals.

22. Pols MA, Peeters PH, Bueno-De-Mesquita HB, Ocke MC, Wentink CA Kemper HC, Collette HJ. Validity and repeatability of a modified Baecke questionnaire on physical activity. Int J Epidemiol. 1995:24(2):381-8.

23. Collaboration ABI, Fowkes FG, Murray GD, Butcher I, Heald CL, Lee RJ, Chambless LE, Folsom AR, Hirsch AT, Dramaix M, et al. Ankle brachial index combined with Framingham risk score to predict cardiovascular events and mortality: a meta-analysis. JAMA. 2008:300(2):197-208.

24. Al-Qaisi M, Nott DM, King DH, Kaddoura S. Ankle brachial pressure index (ABPI): An update for practitioners. Vasc Health Risk Manag. 2009:5:833-41.

25. Prince SA, Adamo KB, Hamel ME, Hardt J, Connor Gorber S, Tremblay M. A comparison of direct versus self-report measures for assessing physical activity in adults: a systematic review. Int J Behav Nutr Phys Activity. 2008:5:56.

26. Paraskevas KI, Kotsikoris I, Koupidis SA, Giannoukas AD, Mikhailidis DP. Ankle-brachial index: a marker of both peripheral arterial disease and systemic atherosclerosis as well as a predictor of vascular events. Angiology. 2010;61(6):521-3.

27. Wei GS, Coady SA, Goff DC Jr, Brancati FL, Levy D, Selvin E, Vasan RS, Fox CS. Blood pressure and the risk of developing diabetes in african Americans and whites: ARIC, CARDIA, and the Framingham heart study. Diabetes Care. 2011;34(4):873-9.

28. Sharma MD, Pavlik VN. Dyslipidaemia in African Americans, Hispanics and whites with type 2 diabetes mellitus and hypertension. Diabetes Obes Metab. 2001:3(1):41-5.

29. Wannamethee SG, Shaper AG, Perry IJ, British Regional Heart Study. Smoking as a modifiable risk factor for type 2 diabetes in middle-aged men. Diabetes Care. 2001;24(9):1590-5.

30. Pinkney JH, Stehouwer CD, Coppack SW, Yudkin JS. Endothelial dysfunction: cause of the insulin resistance syndrome. Diabetes. 1997;46(Suppl 2):S9-13.

31. Meigs JB, Hu FB, Rifai N, Manson JE. Biomarkers of endothelial dysfunction and risk of type 2 diabetes mellitus. JAMA. 2004;291(16):1978-86.

32. Thorand B, Baumert J, Chambless L, Meisinger C, Kolb H, Doring A, Lowel H, Koenig W, MONICA/KORA Study Group. Elevated markers of endothelial dysfunction predict type 2 diabetes mellitus in middle-aged men and women from the general population. Arterioscler Thromb Vasc Biol. 2006:26(2):398-405.

33. Duncan BB, Schmidt MI, Pankow JS, Ballantyne CM, Couper D, Vigo A, Hoogeveen R, Folsom AR, Heiss G, Atherosclerosis Risk in Communities Study. Low-grade systemic inflammation and the development of type 2 diabetes: the atherosclerosis risk in communities study. Diabetes. 2003;52(7):1799-805.

34. Stohr R, Federici M. Insulin resistance and atherosclerosis: convergence between metabolic pathways and inflammatory nodes. Biochem J. 2013;454:1-11.

35. Gkrania-Klotsas E, Ye Z, Cooper AJ, Sharp SJ, Luben R, Biggs ML, Chen LK, Gokulakrishnan K, Hanefeld M, Ingelsson E, et al. Differential white blood cell count and type 2 diabetes: systematic review and meta-analysis of cross-sectional and prospective studies. Plos ONE. 2010;5(10):e13405.

36. Doronina AM, Lipinskĭ B, Bokarev IN. Fibrinogens and their role in atherogenesis in diabetes mellitus. Klin Med (Mosk). 2007;85(7):52-5.

37. Tikellis C, Cooper ME, Thomas MC. Role of the renin-angiotensin system in the endocrine pancreas: implications for the development of diabetes. Int J Biochem Cell Biol. 2006;38(5-6):737-51.

38. Shen L, Shah BR, Reyes EM, Thomas L, Wojdyla D, Diem P, Leiter LA, Charbonnel B, Mareev V, Horton ES, et al. Role of diuretics, beta blockers, and statins in increasing the risk of diabetes in patients with impaired glucose tolerance: reanalysis of data from the NAVIGATOR study. BMJ. 2013;347:f6745

39. Faerch K, Borch-Johnsen K, Holst JJ, Vaag A. Pathophysiology and aetiology of impaired fasting glycaemia and impaired glucose tolerance: does it matter for prevention and treatment of type 2 diabetes? Diabetologia. 2009;52(9):1714-23.

40. Gupta DK, Skali H, Claggett B, Kasabov R, Cheng S, Shah AM, Loehr LR, Heiss G, Nambi V, Aguilar D, et al. Heart failure risk across the spectrum of ankle-brachial index: the ARIC study (Atherosclerosis Risk in Communities). JACC Heart Fail. 2014;2(5):447-54

41. Criqui MH, McClelland RL, McDermott MM, Allison MA, Blumenthal RS, Aboyans V, Ix JH, Burke GL, Liu K, Shea S. The ankle-brachial index and incident cardiovascular events in the MESA (Multi-Ethnic Study of Atherosclerosis). J Am Coll Cardiol. 2010;56(18):1506-12.

42. Korhonen PE, Seppala T, Kautiainen H, Jarvenpaa S, Aarnio PT, Kivela SL. Ankle-brachial index and health-related quality of life. Eur J Prev Cardiol. 2012:19(5):901-7.

43. Ademi Z, Liew D, Gorelik A, Bohensky M, Zomer E, Hollingsworth B, Steg $G$, Bhatt DL, Reid CM, Investigators RR. Predictors of health care use among patients with or at high risk of atherothrombotic disease: twoyear follow-up data. Int J Cardiol. 2014;175(1):72-7.

44. Yokoyama H, Sone H, Honjo J, Okizaki S, Yamada D, Shudo R, Shimizu H, Moriya T, Haneda M. Relationship between a low ankle brachial index and all-cause death and cardiovascular events in subjects with and without diabetes. J Atheroscler Thromb. 2014;21(6):574-81.

45. Gomez-Marcos MA, Recio-Rodriguez II, Gomez-Sanchez L, Agudo-Conde C, Rodriguez-Sanchez E, Maderuelo-Fernandez J, Gomez-Sanchez M, Garcia-Ortiz L, LOD-DIABETES Group. Gender differences in the progression of target organ damage in patients with increased insulin resistance: the LOD-DIABETES study. Cardiovasc Diabetol. 2015;14:132.

46. Katakami N, Osonoi T, Takahara M, Saitou M, Matsuoka TA, Yamasaki Y, Shimomura I. Clinical utility of brachial-ankle pulse wave velocity in the prediction of cardiovascular events in diabetic patients. Cardiovasc Diabetol. 2014;13:128

47. Straznicky NE, Grima MT, Sari Cl, Lambert EA, Phillips SE, Eikelis N, Kobayashi D, Hering D, Mariani JA, Dixon JB, et al. Reduction in peripheral vascular resistance predicts improvement in insulin clearance following weight loss. Cardiovasc Diabetol. 2015;14:113.

48. Cardoso CR, Moran CB, Marinho FS, Ferreira MT, Salles GF. Increased aortic stiffness predicts future development and progression of peripheral neuropathy in patients with type 2 diabetes: the Rio de Janeiro Type 2 Diabetes Cohort Study. Diabetologia. 2015;58(9):2161-8.

49. Maeda Y, Inoguchi T, Etoh E, Kodama Y, Sasaki S, Sonoda N, Nawata $\mathrm{H}$, Shimabukuro M, Takayanagi R. Brachial-ankle pulse wave velocity predicts all-cause mortality and cardiovascular events in patients with diabetes: the Kyushu Prevention Study of Atherosclerosis. Diabetes Care. 2014;37(8):2383-90

50. Norgren L, Hiatt WR, Dormandy JA, Nehler, Harris KA, Fowkes FG, Group TIW, Bell K, Caporusso J, Durand-Zaleski I, et al. Inter-Society Consensus for the Management of Peripheral Arterial Disease (TASC II). Eur J Vasc Endovasc Surg. 2007;33(Suppl 1):S1-75.

51. Murphy TP, Cutlip DE, Regensteiner JG, Mohler ER, Cohen DJ, Reynolds MR, Massaro JM, Lewis BA, Cerezo J, Oldenburg NC, et al. Supervised exercise versus primary stenting for claudication resulting from aortoiliac peripheral artery disease: six-month outcomes from the claudication: exercise versus endoluminal revascularization (CLEVER) study. Circulation. 2012:125(1):130-9. 